American Journal of Environmental Sciences 6 (3): 219-223, 2010

ISSN 1553-345X

(C) 2010 Science Publications

\title{
Wave Characteristics in Sabah Waters
}

\author{
${ }^{1}$ Ejria Saleh, ${ }^{1}$ Jessie Beliku, ${ }^{1}$ Than Aung and ${ }^{2}$ Awnesh Singh \\ ${ }^{1}$ Borneo Marine Research Institute, University Malaysia Sabah, Locked Bag 2073, \\ 88999 Kota Kinabalu, Sabah, Malaysia \\ ${ }^{2}$ Laboratory Studies in Geophysics and Oceanography Space, \\ 14 Avenue Edouard Belin, 31400 Toulouse France
}

\begin{abstract}
Problem statement: This study was conducted to identify and compare the wave characteristics in Sabah waters at five different key locations so as to determine the effects of the Northeast Monsoon (NEM) and the Southwest Monsoon (SWM) along the east and west coasts of Sabah. Approach: Monthly wave height and wave period data for 8 years covering offshore areas of Labuan, Kota Kinabalu (KK), Kudat, Sandakan and Tawau were collected from the Meteorological Department, Sabah Branch. The data was analyzed at different areas through the Probability Density Function (PDF) to estimate the most likely wave height and wave period in the study area. Wave power was also calculated using the wave power formula to identify the strength of waves in Sabah waters. The significance of wave characteristics during the NEM and the SWM for the east coast (Sandakan and Tawau) and west coast (Labuan and KK) of Sabah are presented in this study. Results: The range of wave heights in coastal waters surrounding Sabah was found to be $0.5-2 \mathrm{~m}$. Wave height is usually higher than $1 \mathrm{~m}$ in the west coast during NEM while the east coast has a wave height of $\sim 0.5 \mathrm{~m}$ for both monsoons. The wave power per unit width in the west coast is significantly higher $\left(\sim 5 \mathrm{~kW} \mathrm{~m}^{-1}\right)$ especially during NEM than during SWM. The wave power in the east coast is less than $1 \mathrm{~kW} \mathrm{~m}^{-1}$ for both monsoons. Conclusion: The findings of this study can be useful for local fishermen in navigation purpose and coastal zone management activities.
\end{abstract}

Key words: Wave characteristics, Sabah, coastal waters, seasonal monsoons

\section{INTRODUCTION}

Knowledge of sea waves is necessary for all maritime activities including the behavior and occurrence of pelagic fish (Reddy, 2001). Turbulence associated with sea waves promotes interchange between the sea and atmosphere, as well as circulation and distribution of oxygen, heat and other elements within the upper layer of the ocean (Moon, 2005). Wave induced currents are primarily responsible for transportation and deposition of near shore sediments (Castelle et al., 2006). Thus, waves play the dominant role in determining the configuration of the coastline and associated shoreline features. Waves proved to play an important role in the distribution of suspended sediment concentrations and bed form activities where accumulation of some classes of nutrients and pesticides are evident (Schneggenburger et al., 2000; Lee et al., 2004). Suspended particulate matter in a water column increases turbidity (Singh, 2008) and reduces the available solar radiation for the photosynthetic activity of phytoplankton (BarettaBekker et al., 1998). Apart from high wind speeds and increased mean water levels at landfall, wave heights associated with Tropical Cyclones (TC) pose a major hazard. It is to be noted that Sabah, Malaysia (Fig. 1), does not experience cyclones very often due to its closeness to the equator, but TC Greg in 1997 was a severe one in the recent years.

Information on waves is valuable for fishermen and can minimize resources wasted. The wave conditions can determine the depth of the mixed layer in the upper layer and thus help determine the most appropriate fishing gear for fishing activity in an area (Reddy, 2001). Knowledge of wave characteristics is essential for the planning, design and construction of new ports coastal protection constructions, harbors and navigational channels (Schneggenburger et al., 2000; Sundar and Ananth, 1988) and it also contributes to fisheries activities, navigation, marine habitat management and coastal development and planning.

Corresponding Author: Awnesh Singh, Laboratory Studies in Geophysics and Oceanography Space, 14 Avenue Edouard Belin, 31400 Toulouse, France 
The objectives of this study are to identify wave characteristics for waters off the east and west coasts of Malaysia. Wave characteristics in these areas are also used to determine the highest wave height during the Northeast Monsoon (NEM) and the Southwest Monsoon (SWM) of waters off the east coast and west coast of Sabah. The findings of this study would aid further researches conducted in modeling and prediction of tropical cyclones.

\section{MATERIALS AND METHODS}

The study area: Study of wave characteristics in Sabah (northern tip of Borneo Island) is conducted at the seas surrounding Sabah which consist of the South China Sea, Sulu Sea and Celebes Sea (Fig. 1). Monsoonal climate has a strong influence in this area (Wyrtki, 1961). The NEM and SWM, which occur respectively between November and February and June and September, changes the surface current circulation of the sea (Babu et al., 2005). However, it is to be noted that the timing of monsoonal periods can vary and is not rigid due to the unpredictable wind stress. The South China Sea is one of the world's largest seas that encompasses approximately 200 isolated oceanic islands and are considered to be within the epicenter of tropical reef biodiversity (TRACC, 2001). The Sulu Sea is an enclosed sea, like the Mediterranean Sea, isolated from the surrounding water by a chain of islands: Borneo Island in the southwest, Palawan in the west, Busuanga and Mindoro in the north, Panay, Negros and Mindanao in the east and the Sulu Archipelago in the southeast (Wang et al., 2006). The Celebes Sea in the western Pacific Ocean has strong ocean currents resulting in complex oceanographic features of deep sea trenches and sea mounts combined with active volcanic islands (Wyrtki, 1961).

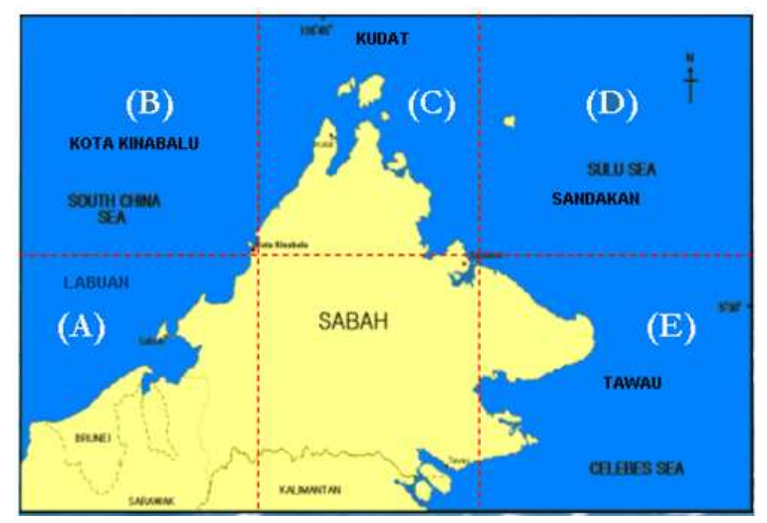

Fig. 1: Map of Sabah showing the areas of Labaun (A), Kota Kinabalu (B), Kudat (C), Sandakan (D) and Tawau (E)
Data: Monthly wave data for the an 8 year period was obtained from the Meteorological Department, Sabah Branch. The data was collected by selected merchant ships passing through the waters of the South China Sea, Sulu Sea and Celebes Sea. Wave data is selected according to the closest main towns of Labuan, Kota Kinabalu, Kudat, Sandakan and Tawau to represent waters off these areas. Having digitized the data for the locations indicated, the data was analyzed through the Probability Density Function (PDF); (Silverman, 1986). Data collected from Labuan and Kota Kinabalu was later combined to represent the west coast of Sabah to study the effect of the monsoonal seasons from the South China Sea while data collected from Sandakan and Tawau was combined to represent the east coast of Sabah. Wave data are analyzed based on wave height and wave period.

\section{RESULTS}

Variation of wave height: Similar trends in wave heights but with low values were observed off Sandakan and Tawau waters (Fig. 2) in contrast to the wave heights off Labuan, Kota Kinabalu and Kudat which display the trends with higher values in the PDF variation. The PDF curve indicates that the highest number of wave heights recorded in the waters off Sandakan and Tawau is $0.5 \mathrm{~m}$. Wave heights that were frequently observed at waters off Labuan, Kota Kinabalu and Kudat ranges between 0.6-1 m. It indicates that the wave height is higher in the western side of Sabah facing the South China Sea.

Variation of wave period: The wave period of west coast of Sabah are mostly recorded between 2-4 sec (Fig. 3). The PDF curve for Sandakan waters has a peak at $3 \mathrm{sec}$ while for Tawau waters, it is at $2 \mathrm{sec}$. Most wave periods at waters off Labuan, Kota Kinabalu and Kudat are recorded at 3 and $4 \mathrm{sec}$. The range for the wave period in Sabah waters is between 1-6 sec.

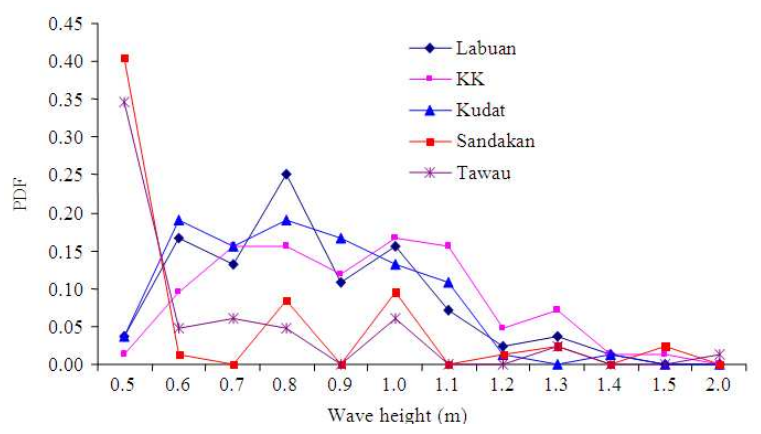

Fig. 2: Probability distributions of wave heights 
Am. J. Environ. Sci., 6 (3): 219-223, 2010

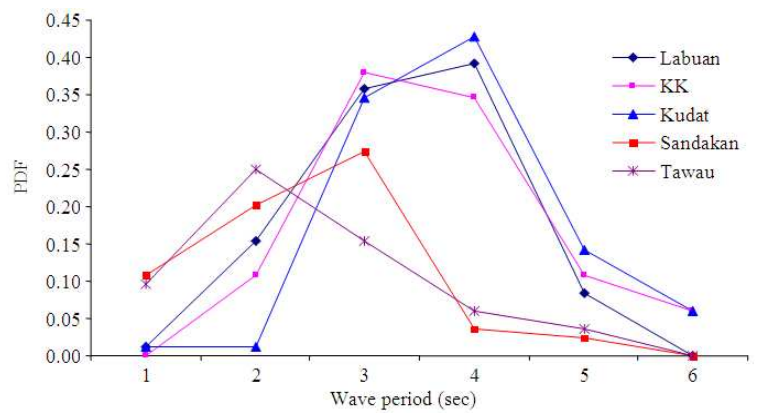

Fig. 3: Probability distribution of wave periods

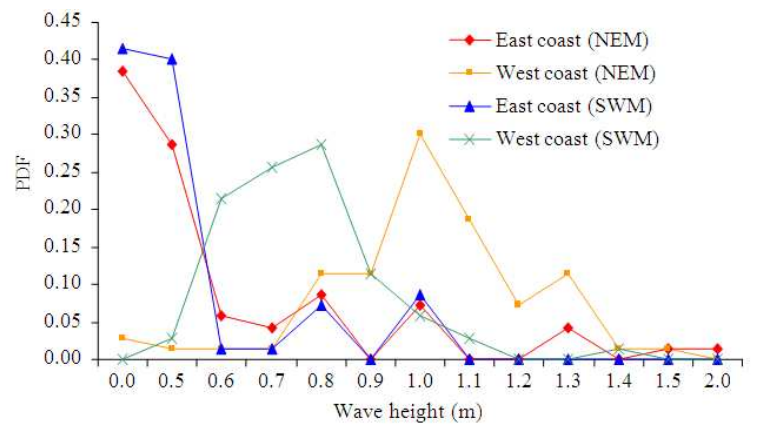

Fig. 4: Probability distribution of wave height according to area and monsoonal seasons

Wave heights during monsoonal periods: The variation of wave height through the PDF can be seen for the west and east coasts during the monsoonal seasons (Fig. 4). It is to be noted that west coast of Sabah here is represented by the data from Labuan and Kota Kinabalu areas and the east coast is from the data of Sandakan and Tawau areas. The data from Kudat, at the northern tip of the island is not included in the PDF analysis as it is in the middle and can either represent the east or west of Sabah. The wave height most commonly recorded for the east coast during both monsoonal seasons is $0.5 \mathrm{~m}$. Wave heights recorded off the west coast during the NEM are in a higher range $(0.9-1.2 \mathrm{~m})$ with the highest probability at $1 \mathrm{~m}$. Meanwhile, wave heights recorded during the SWM were in a lower range $(0.6-0.9 \mathrm{~m})$ with a peak likelihood at $0.8 \mathrm{~m}$. We can infer that the waves are significantly taller in the west coast of Sabah than in the east coast.

Wave periods during monsoonal periods: The trends in wave period are almost the same for the east coast of Sabah during both monsoonal seasons (Fig. 5). Both monsoonal seasons of Sabah's east coast show higher occurrence of wave period frequency at 2 and $3 \mathrm{sec}$. The maximum value for the PDF curve for waters off the west coast in both monsoonal seasons is $3 \mathrm{sec}$.

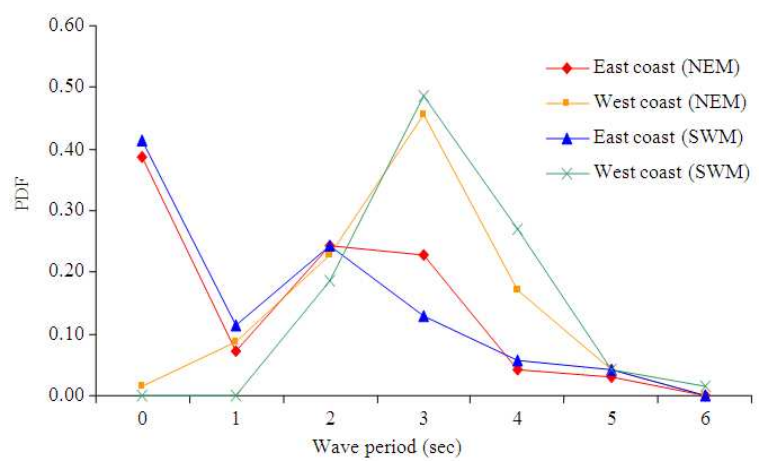

Fig. 5: Cumulative probability distribution of wave period according to area and monsoonal seasons

\section{DISCUSSION}

The wave heights for all five locations of Sabah waters is found to vary between 0.5 and $1.5 \mathrm{~m}$ with wave height in Tawau area reaching up to a maximum of $2 \mathrm{~m}$ (Table 1). Waters of all five areas are considered calm and do not enter any criteria for rough sea. However, this may not be entirely true as there are no observations from ships during harsh sea conditions (some ships do not sail during this period). Waters off Labuan, Sandakan and Tawau share the same range of wave period $(1-5 \mathrm{sec})$ while wave periods off Kota Kinabalu and Kudat waters vary from 2-6 and 1-5 sec, respectively.

Higher wave heights are recorded off Labuan, Kota Kinabalu and Kudat. The larger area of the South China Sea allows the strength of wind to create the area into a fully developed sea compared to the Sulu and Celebes seas on the east coast. The west coast area is also very much exposed as it is not sheltered by offshore islands and directly faces the monsoonal winds. For areas off the east coast of Sabah (Sandakan and Tawau), where the areas are smaller in size and surrounded by the Philippines islands and Indonesian Archipelagos, the highest probability of wave heights occurrence is about $0.5 \mathrm{~m}$ (Table 2). The wave period for Labuan, Kota Kinabalu and Kudat occurs more frequently at 3-4 sec while the wave periods for Sandakan and Tawau are more frequent at 2-3 sec (Fig. 3). However, it is to be noted that wave data collected in the east coast area is relatively less than the data in the west.

Wave power calculation during monsoonal periods: Wave power is calculated using the wave power equation (Pond and Pickard, 1991) to estimate the strength of wave in the local water (Eq. 1): 
Am. J. Environ. Sci., 6 (3): 219-223, 2010

$\mathrm{P}=\frac{\rho^{2}}{32 \pi} \mathrm{HT}$

Where:

$\rho=$ The average seawater density

$\mathrm{g}=$ Acceleration due to gravity

$\mathrm{H}=$ The wave height

$\mathrm{T}=$ The wave period

$\mathrm{P}=$ The wave power per unit length $\left(\mathrm{kW} \mathrm{m}^{-1}\right)$ of wave front

As indicated earlier, the range of wave height in the east coast is more varied than the west coast during the NEM but is opposite during the SWM. However, the wave period range is almost the same for the west and east coasts for both monsoonal seasons (Table 3). Both sides of the coasts in Sabah waters have a wide range of wave power during the NEM with the range wider in the west coast.

Table 1: Wave height range and period in Sabah waters

\begin{tabular}{lll} 
& Wave range & \\
Area & - & \\
\hline Labuan & Height $(\mathrm{m})$ & Period $(\mathrm{sec})$ \\
Kota Kinabalu & $0.5-1.4$ & $1-5$ \\
Kudat & $0.5-1.5$ & $2-6$ \\
Sandakan & $0.5-1.4$ & $1-6$ \\
Tawau & $0.5-1.5$ & $1-5$ \\
\hline
\end{tabular}

Table 2: Highest probability of occurrences for wave characteristics Highest probability of occurrences

\begin{tabular}{lll} 
Area & Wave height $(\mathrm{m})$ & Wave period $(\mathrm{sec})$ \\
\hline Labuan & 0.8 & $3-4$ \\
Kota Kinabalu & $0.7-1.1$ & $3-4$ \\
Kudat & $0.6-1.0$ & $3-4$ \\
Sandakan & 0.5 & $2-3$ \\
Tawau & 0.5 & $2-3$ \\
\hline
\end{tabular}

Table 3: Wave power during the NEM and SWM

\begin{tabular}{llll}
\hline & Wave characteristics & \\
& - & & \\
Area & Height $(\mathrm{m})$ & Period $(\mathrm{sec})$ & Power $\left(\mathrm{kWm}^{-1}\right)$ \\
\hline West coast $(\mathrm{NEM})$ & $0.5-1.5$ & $1-5$ & $0.6-13.9$ \\
East coast (NEM) & $0.5-2$ & $1-5$ & $0.3-19.7$ \\
West coast (SWM) & $0.5-1.4$ & $1-5$ & $0.9-12.1$ \\
East coast (SWM) & $0.5-1$ & $1-5$ & $0.3-6.20$ \\
\hline
\end{tabular}

Table 4:Maximum probable wave height and wave period and associated wave energy

\begin{tabular}{llll}
\hline & \multicolumn{2}{l}{ Highest probability of occurrences } \\
& ------------------------- \\
Area & Height $(\mathrm{m})$ & Period $(\mathrm{sec})$ & Power $\left(\mathrm{kWm}^{-1}\right)$ \\
\hline West coast (NEM) & $1-1.1$ & $2-3$ & 4.9 \\
East coast (NEM) & 0.5 & $2-3$ & $0.6-0.9$ \\
West coast (SWM) & $0.6-0.8$ & $2-4$ & $1.8-3.2$ \\
East coast (SWM) & 0.5 & $1-3$ & $0.3-0.6$ \\
\hline
\end{tabular}

The most probable wave heights and periods were used for wave power calculation and the final results are given in Table 4. The waters in the west coast experiences higher wave heights in comparison to the east coast both during the NEM and SWM. The highest wave height occurred during the NEM. However, no obvious effect of both monsoons is seen in the east coast. The PDF curve for the east coast for both monsoonal seasons shows a similar trend (Fig. 5) but the number of lower wave heights is observed during the SWM. During the NEM, the highest probability of wave periods is the same for both coasts whereas during the SWM, the wave period for the west coast is higher than the east coast. The west coast has higher wave period during the NEM whereas the east coast has higher wave period during the SWM (Table 4).

The generation of waves is mainly dependent on wind speed and direction. For instance, the Labuan area experiences winds mainly from the north and northeast while the Kota Kinabalu area is generally dominated by the northeast winds. The west coast is dominated by winds from the north and northeast which are present during the NEM. Sandakan and Tawau areas experience northeast winds throughout the year. The different monsoon seasons does not seem to have obvious effect on the east coast.

\section{CONCLUSION}

The waters off Sabah are mostly calm, with wave heights ranging from $0.5-1.5 \mathrm{~m}$ and wave periods ranging from 1-5 sec. Wave height is usually higher $(>1 \mathrm{~m})$ in the west coast during NEM than SWM while the east coast has more or less the same wave height for both monsoons. The small monsoonal effect in the east coast is due to the geographical positioning (the land is blocking the southwest winds during SWM) and the size of its surrounding seas which are relatively smaller. Within our capacity and limited study, at least we can say that wave power $\left(\sim 5 \mathrm{~kW} \mathrm{~m}^{-1}\right)$ in the west coast is significantly higher, especially during NEM. However, many factors affect the accuracy of the data used in this study. Nonetheless, this study provides an overview of recorded wave characteristics which can be used for further study as well as coastal zone management around Sabah. More detailed studies are recommended through continuous data recording using wave gauges, satellites imagery analysis and numerical modeling.

\section{REFERENCES}

Babu, M.T., P. Vethamony and E. Desa, 2005. Modelling tide-driven currents and residual eddies in the Gulf of Kachchh and their seasonal variability: A marine environmental planning perspective. Ecolog. Model., 184: 299-312. 
Baretta-Bekker, J., E. Duursma and B. Kuipers, 1998. Encyclopaedia of Marine Sciences. 2nd Edn., Springer Verlag, Berlin, pp: 357.

Castelle, B., P. Bonneton, N. Senechal, H. Dupuis, R. Butel and D. Michel, 2006. Dynamic of waveinduced currents over an alongshore non-uniform multiple-barred sandy beach on the Aquitanian Coast, France. Cont. Shelf Res., 26: 113-131.

Lee, H.J., H.R. Jo, Y.S. Chu and K.S. Bahk, 2004. Sediment transport on Macrotidal flats in Garolim Bay, west coast of Korea: Significance of wind waves and asymmetry of tidal currents. Cont. Shelf Res., 24: 821-832.

Moon, I.J., 2005. Impact of a coupled ocean wave-tidecirculation system on coastal modeling. Ocean Model., 8: 203-236.

Pond, S. and G.J. Pickard, 1991. Introductory Dynamical Oceanography. 2nd Edn., Pergamon Press, Oxford OX3 0BW, England, pp: 329.

Reddy, M.P.M., 2001. Descriptive Physical Oceanography. A.A. Balkema Publishers, Mangalore, ISBN: 90-5410-706-5, pp: 440.

Schneggenburger, C., H. Gunther and W. Rosenthal, 2000. Spectral wave modeling with non-linear dissipation: Validation and applications in a coastal tidal environment. Coast. Eng., 41: 201-235.
Silverman, B.W., 1986. Density Estimation for Statistics and Data Analysis, Chapman and Hall, London, pp: 175.

Singh, A., 2008. Salinity, Temperature and turbidity structure in the Suva Lagoon. Am. J. Environ. Sci., 4: 252-261.

Sundar, V. and P.N. Ananth, 1988. Wind climate for madras harbor, India. J. Wind Eng. Ind. Aerodynam., 31: 323-333.

Tropical Research and Conservation Centre, (TRACC), 2001. Weather in Borneo: Monsoon, Wind and Rain. http://www.tracc.org.my/

Wang, J., Y. Qi and I.S.F. Jones, 2006. An analysis of the characteristics of chlorophyll in the Sulu Sea. J. Mar. Syst., 59: 111-119.

Wyrtki, K., 1961. Physical Oceanography of the Southeast Asian Waters. The University of California Scripps Institution of Oceanography La Jolla, California. 